\title{
Analysis of genetic diversity in Larix gmelinii (Pinaceae) with RAPD and ISSR markers
}

\section{Zhang ${ }^{1}$, H.G. Zhang ${ }^{1}$ and X.F. Li $^{2}$}

${ }^{1}$ State Key Laboratory of Forest Genetics and Tree Breeding, Northeast Forestry University, Harbin, China

${ }^{2}$ Liaoning Forest Inventory and Planning Institute, Shenyang, Liaoning, China

Corresponding authors: H.G. Zhang

E-mail: hanguozhang1@yahoo.com.cn

Genet. Mol. Res. 12 (1): 196-207 (2013)

Received April 27, 2012

Accepted October 26, 2012

Published January 24, 2013

DOI http://dx.doi.org/10.4238/2013.January.24.12

\begin{abstract}
Dahurian larch (Larix gmelinii), a deciduous conifer, is the northernmost tree, native to eastern Siberia and nearby regions of China. We used growth traits and molecular markers to assess genetic variation in different L. gmelinii growing regions; 105 individual samples were collected from seven regions of the Qingshan Forestry Centre, Heilongjiang Province, China. The greatest genetic regional variation was seen in the Youhao area, based on coefficients of variation for tree height, diameter and volume (14.73, 28.25, and $55.27 \%$, respectively). Analysis using molecular markers showed rich genetic diversity. The RAPD and ISSR methods both indicated that most variation came from within populations. The seven regions were divided into two groups (Daxing'an and Xiaoxing'an Mountain ranges) by RAPD cluster analysis: Tianchi, Xiaojiuya, Yuanjiang, and Taiping regions were placed in the first group at a genetic distance of 0.08 ; while the other regions were in the second group. The correlation
\end{abstract}


between RAPD markers and geographical distance was significant, with a correlation coefficient of 0.752 .

Key words: Genetic diversity; Inter-simple sequence repeat; Growth traits; Random amplified polymorphic DNA;

Larix gmelinii (Rupr.)

\section{INTRODUCTION}

Genetic improvements in larch (Larix gmelinii) have been mainly based on the establishment of seed orchards, breeding, and propagation using cuttings (Larionova et al., 2004; Oreshkova et al., 2006). More intensive research on L. gmelinii has led to analyses of genetic diversity through morphological, cytological (chromosomal), and isozyme approaches (Changtragoon, 1995; Zhang et al., 2002), but it has yielded relatively poor results. More recent studies have examined regional genetic diversity using molecular markers that have become popular, such as random amplified polymorphic DNA (RAPD) and inter-simple sequence repeats (ISSR) (Bucci et al., 1997; Goto et al., 1998; Li, 2004; Shahraji et al., 2009). These studies include research on genetic differentiation in conifer species such as spruce and pine (Liu et al., 2005; Labra et al., 2006; Xue et al., 2007).

The present study used individual samples as a way to reflect real genetic resources in various regions and understand the interaction between growth traits and genes. We analyzed genetic diversity using 2 molecular techniques (RAPD and ISSR) and phenotypic growth traits to evaluate geographic resources accurately and objectively and contribute to research on genetic variation in L. gmelinii.

\section{MATERIAL AND METHODS}

\section{Sample collection}

During June 2007, 15 individual samples of $L$. gmelinii conifers were collected from 7 regions in sample collection areas (49 and 53 areas) of Qingshan Forestry Centre, Linkou County, Heilongjiang Province. This forest was planted in April 1985 and includes 7 regions: Tianchi in the Aershan District (AES; samples 1006-1057), Xiaojiuya in the Kuduer District (KDE; samples 1101-1147), Taiping in the Moerdaoga District (MEDG; samples 1204-1267), Yuanjiang in the Ganhe District (GH; samples 1305-1360), Zhongyangzhan in the Nanjiang District (NJ; samples 1407-1464), Youhao in the Yichun District (YCYH; samples 15311570), and Qianwei in the Wuyiling District (WYL; samples 1602-1666).

Total DNA was extracted from frozen $\left(-80^{\circ} \mathrm{C}\right)$ conifer tissue using a standard hexadecyltrimethylammonium bromide method (Porebski et al., 1997). DNA was detected with electrophoresis on $0.8 \%$ agarose gels, and the concentration was quantified with an Eppendorf BioPhotometer and normalized to a concentration of $30 \mathrm{ng} / \mu \mathrm{L}$.

\section{Polymerase chain reaction (PCR) amplification}

Twenty-one individual samples (3 per area) were initially screened with 400 RAPD and 300 ISSR primers (Sangon, Shanghai, China). Twenty-three RAPD and 21 ISSR primers 
(Table 1) were selected for further analysis, as they repeatedly amplified clear polymorphic bands.

\begin{tabular}{|c|c|c|c|c|c|}
\hline Primer & Sequences $\left(5^{\prime}-3^{\prime}\right)$ & Primer & Sequences $\left(5^{\prime}-3^{\prime}\right)$ & Primer & Sequences $\left(5^{\prime}-3^{\prime}\right)$ \\
\hline S222 & AGTCACTCCC & S1500 & CTCCGCACAG & Y11 & ACACACACACACACACGAC \\
\hline S228 & GGACGGCGTT & S2141 & CCGACTCTGG & $\mathrm{Y} 22$ & ACACACACACACACACGAG \\
\hline S282 & CATCGCCGCA & S2152 & TCGCCTTGTC & $\mathrm{Y} 24$ & ACACACACACACACACGTA \\
\hline S320 & CCCAGCTAGA & S2156 & CTGCGGGTTC & Y27 & ACACACACACACACACGTT \\
\hline S362 & GTCTCCGCAA & OPA-15 & TTCCGAACCC & Y33 & ACACACACACACACACTAT \\
\hline S369 & CCCTACCGAC & OPD-06 & ACCTGAACGG & Y36 & ACACACACACACACACTGG \\
\hline S407 & CCGTGACTCA & OPD-15 & CTCACGTTGG & Y41 & ACACACACACACACACCCT \\
\hline S418 & CACCATCCGT & OPN-01 & CTCACGTTGG & Y42 & ACACACACACACACACGAA \\
\hline S477 & TGACCCGCCT & Y18R & ACACACACACACACACCG & Y134R & ACACACACACACACACGTT \\
\hline S511 & GTAGCCGTCT & Y23L & AGAGAGAGAGAGAGAGGG & Y139R & ACACACACACACACACGGA \\
\hline S1135 & TGATGCCGCT & Y38R & ACACACACACACACACGG & YS3 & GACAGACAGACAGACA \\
\hline S1361 & TCGGATCCGT & Y40R & ACACACACACACACACAAC & Y44 & ACACACACACACACACCTT \\
\hline S1371 & TCCAGCGCGT & Y58R & ACACACACACACACACCTT & Y45 & ACACACACACACACACTAT \\
\hline S1377 & CACGCAGATG & Y90R & ACACACACACACACACTTT & Y14L & AGAGAGAGAGAGAGAGTC \\
\hline S1379 & ACACTCTCGG & Y123R & ACACACACACACACACCGA & & \\
\hline
\end{tabular}

ISSR $=$ inter-simple sequence repeat; RAPD $=$ random amplified polymorphic DNA.

RAPD was performed in a $20-\mu \mathrm{L}$ volume containing $50 \mathrm{ng}$ DNA, $1 \mathrm{X}$ reaction buffer (TaKaRa, Dalian, China), $2.5 \mathrm{mM} \mathrm{MgCl}$ (TaKaRa), $0.25 \mathrm{mM}$ deoxyribonucleotide triphosphates (TaKaRa), $0.5 \mu \mathrm{M}$ primers (Sangon), and $1 \mathrm{U}$ Taq DNA polymerase (TaKaRa). RAPDPCR was carried out for a cycle of $3 \mathrm{~min}$ at $94^{\circ} \mathrm{C}$, followed by 40 cycles of $1 \mathrm{~min}$ at $94^{\circ} \mathrm{C}, 1$ min at $37^{\circ} \mathrm{C}$, and $1.5 \mathrm{~min}$ at $72^{\circ} \mathrm{C}$, and a final cycle of $7 \mathrm{~min}$ at $72^{\circ} \mathrm{C}$.

ISSR was performed in a $20-\mu \mathrm{L}$ volume containing 50 ng DNA, $1 \mathrm{X}$ reaction buffer (TaKaRa), $2.5 \mathrm{mM} \mathrm{MgCl}$ (TaKaRa), $0.2 \mathrm{mM}$ deoxyribonucleotide triphosphates (TaKaRa), $0.5 \mu \mathrm{M}$ primers (Sangon), and $1 \mathrm{U}$ Taq DNA polymerase (TaKaRa). ISSR amplification was carried out for a cycle of $3 \mathrm{~min}$ at $94^{\circ} \mathrm{C}$, followed by 35 cycles of $30 \mathrm{~s}$ at $94^{\circ} \mathrm{C}, 45 \mathrm{~s}$ at $56^{\circ} \mathrm{C}$, and $45 \mathrm{~s}$ at $72^{\circ} \mathrm{C}$, and a final cycle of $7 \mathrm{~min}$ at $72^{\circ} \mathrm{C}$. The amplified products from both procedures were separated with electrophoresis using $1.5 \%$ agarose gels.

\section{Data analysis}

Height, diameter, and volume for every specimen were calculated with SPSS 15.0 for multiple comparison and variance analysis. The volume was calculated using a mean based on the formula $\mathrm{V}=0.32(\mathrm{~h}+3) \mathrm{d}^{2}$, where $V$ is volume, $h$ is height, and $d$ is diameter.

PCR products were scored as present (1) or absent (0) bands for each population and analyzed. Based on the binary matrix obtained in this study, genetic diversity indexes were calculated in the dominant diploid of POPGENE version 1.32 (Yeh et al., 1999).

\section{RESULTS}

\section{Growth character genetic variation of individual samples and regions}

Variation was found among the L. gmelinii specimens taken from each of the 7 regions with respect to height, diameter, and volume (Table 2). The coefficients of variation were $12.69-17.38,18.03-28.25$, and $41.67-55.27 \%$, whereas the variation range was $6.20-16.5$ 
$\mathrm{m}, 4.80-28.9 \mathrm{~cm}$, and $0.01-0.47 \mathrm{~m}^{3}$, respectively. Specimens from the YCYH, NJ, and MEDG regions showed more variation in volume compared to those in the other 4 zones. A difference of $13.6 \%$ was found between the YCYH and KDE regions in the coefficient of variation for volume. The coefficients of variation for the YCYH regional specimens for height, diameter, and volume were $14.73,28.25$, and $55.27 \%$, respectively, and for specimens from the KDE region, minimum variance was $12.69,18.03$, and $41.67 \%$, respectively.

Table 2. Variation of the growth characteristics among the regions of Larix gmelinii.

\begin{tabular}{|c|c|c|c|c|c|c|c|}
\hline Traits & Regions & Number & Mean & $\mathrm{SD}$ & Coefficient of variation (\%) & Error & Variation (range) \\
\hline \multirow[t]{8}{*}{ Height (m) } & AES & 60 & 10.695 & 1.605 & 15.01 & 0.207 & $6.90-14.90$ \\
\hline & $\mathrm{KDE}$ & 76 & 12.341 & 1.566 & 12.69 & 0.180 & $8.60-16.10$ \\
\hline & MEDG & 76 & 10.962 & 1.593 & 14.54 & 0.183 & $6.60-14.30$ \\
\hline & GH & 63 & 11.268 & 1.766 & 15.67 & 0.222 & $6.20-14.90$ \\
\hline & NJ & 74 & 11.455 & 1.991 & 17.38 & 0.231 & $7.00-16.50$ \\
\hline & YCYH & 73 & 12.156 & 1.790 & 14.73 & 0.210 & $7.20-15.20$ \\
\hline & WYL & 76 & 11.308 & 1.616 & 14.29 & 0.185 & $7.60-14.60$ \\
\hline & Total & 498 & 11.480 & 1.787 & 15.57 & 0.080 & $6.20-16.50$ \\
\hline \multirow[t]{8}{*}{ Diameter $(\mathrm{cm})$} & AES & 60 & 16.458 & 3.586 & 21.79 & 0.463 & $8.80-25.50$ \\
\hline & KDE & 76 & 18.729 & 3.377 & 18.03 & 0.387 & $7.40-28.20$ \\
\hline & MEDG & 76 & 17.520 & 4.034 & 23.03 & 0.463 & $7.20-28.90$ \\
\hline & GH & 63 & 17.465 & 3.611 & 20.68 & 0.455 & $8.10-25.10$ \\
\hline & $\mathrm{NJ}$ & 74 & 17.314 & 4.536 & 26.20 & 0.527 & $8.10-25.00$ \\
\hline & YCYH & 73 & 17.921 & 5.062 & 28.25 & 0.592 & $4.80-28.90$ \\
\hline & WYL & 76 & 17.379 & 3.298 & 18.98 & 0.378 & $9.10-24.60$ \\
\hline & Total & 498 & 17.576 & 4.012 & 22.83 & 0.180 & $4.80-28.90$ \\
\hline \multirow[t]{8}{*}{ Volume $\left(\mathrm{m}^{3}\right)$} & AES & 60 & 0.129 & 0.065 & 50.41 & 0.008 & $0.02-0.34$ \\
\hline & $\mathrm{KDE}$ & 76 & 0.182 & 0.076 & 41.67 & 0.009 & $0.02-0.47$ \\
\hline & MEDG & 76 & 0.149 & 0.076 & 50.55 & 0.009 & $0.02-0.38$ \\
\hline & GH & 63 & 0.150 & 0.072 & 47.98 & 0.009 & $0.02-0.35$ \\
\hline & NJ & 74 & 0.155 & 0.084 & 54.54 & 0.010 & $0.02-0.35$ \\
\hline & YCYH & 73 & 0.175 & 0.097 & 55.27 & 0.011 & $0.01-0.40$ \\
\hline & WYL & 76 & 0.148 & 0.066 & 44.54 & 0.008 & $0.03-0.34$ \\
\hline & Total & 498 & 0.156 & 0.079 & 50.38 & 0.004 & $0.01-0.47$ \\
\hline
\end{tabular}

AES = Aershan District; KDE $=$ Kuduer District; MEDG = Moerdaoga District; $\mathrm{GH}=$ Ganhe District; NJ = Nanjiang District; YCYH = Yichun District; WYL = Wuyiling District; SD = standard deviation.

The height, diameter, and volume of individual samples varied greatly: the coefficients of variation were $1.25-26.69 \%($ mean $=15.57 \%), 3.74-46.43 \%($ mean $=28.3 \%)$, and $10.21-94.25 \%($ mean $=50.38 \%)$, respectively. The 5 individual samples with the greatest variation in volume were sample Nos. 1555 (94.25\%), 1007 (89.27\%), 1553 (74.17\%), $1031(74.00 \%)$, and $1531(71.19 \%)$. Three of these samples came from YCYH, and 2 were from AES. The 5 individual samples with the smallest variation in volume were Nos. 1464 (10.21\%), $1353(10.94 \%), 1024(12.11 \%), 1128(13.60 \%)$, and $1461(14.33 \%)$ and were from the NJ, GH, AES, KDE, and NJ regions, respectively. The difference between the largest and smallest coefficients of variation was $84.04 \%$. Large variation between regions and individual samples is beneficial for selection; therefore, it is important to pay attention not only to good regional selection but also to good individual specimens.

\section{Regional genetic variance analysis of molecular markers}

\section{Amplification results of RAPD and ISSR}

For the 7 regions (105 samples) of L. gmelinii, 23 RAPD primers generated 189 
fragments that ranged in size from 300 to $3000 \mathrm{bp}$, and the percentage of polymorphic loci was $97.35 \%$ (184 locus polymorphisms). The 21 ISSR primers generated 171 fragments that ranged in size from 300 to $2300 \mathrm{bp}$, and the percentage of polymorphic loci was $98.83 \%$ (169 locus polymorphisms), which was slightly higher than that found with RAPD. Different primer amplification of the 2 markers resulted in electrophoresis maps of many bands and differently sized fragments (Figures 1 and 2).

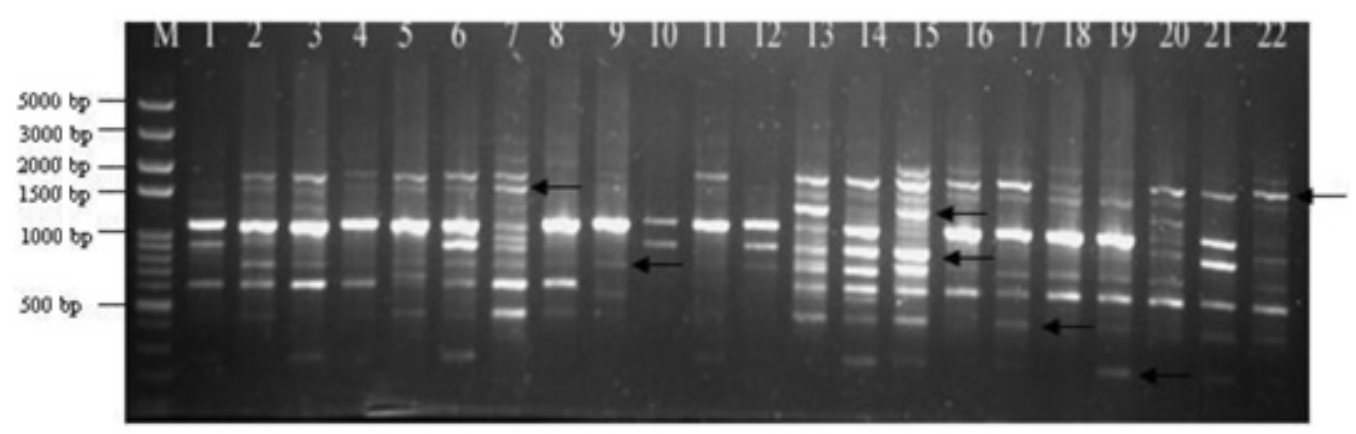

Figure 1. Random amplified polymorphic DNA amplification results of representative DNA samples using S1377 primer. Lanes 1 to 15 were from the Tianchi region in the Aershan District (AES); lanes 16 to 22 were from the Xiaojiuya region in Kuduer District (KDE). Arrows indicate polymorphic loci.

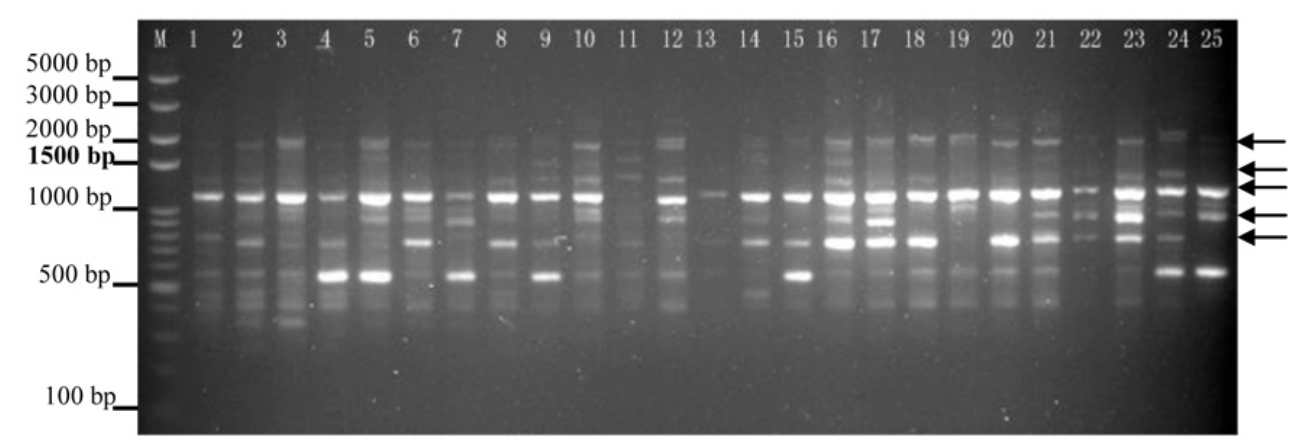

Figure 2. Inter-simple sequence repeat amplification results of representative DNA samples using Y24 primer. Lanes 1 to 15 were from the Tianchi region in the Aershan District (AES); lanes 16 to 22 were from the Xiaojiuya region in Kuduer District (KDE). Arrows indicate polymorphic loci.

\section{Genetic diversity of regions}

Using the RAPD and ISSR amplification results, we analyzed the genetic diversity of the 7 regions (Table 3). The range of the mean number of alleles based on RAPD analysis was 1.8307-1.8889, the effective number of alleles $\left(N_{\mathrm{E}}\right)$ was 1.5119-1.5498, the Shannon information index ( $I$ ) was $0.4382-0.4764$, the Nei gene diversity index (heterozygosity; $H$ ) was $0.2948-0.3200$. The range of the mean number of alleles based on ISSR was 1.8421-1.9006, $N_{\mathrm{E}}=1.5565-1.6417, I=0.4664-0.5221$, and $H=0.3166-0.3584$. The order of the 7 regions based on $I$ was the same as that found for $H$ using RAPD and ISSR data. 


\begin{tabular}{|c|c|c|c|c|c|c|c|c|c|}
\hline Marker & Index & AES & $\mathrm{KDE}$ & MEDG & GH & NJ & YCYH & WYL & All \\
\hline \multirow[t]{5}{*}{ RAPD } & $N_{\mathrm{A}}$ & 1.8360 & 1.8889 & 1.8307 & 1.8413 & 1.8466 & 1.8624 & 1.8677 & 1.9735 \\
\hline & $N_{\mathrm{E}}^{\mathrm{A}}$ & 1.5432 & 1.5498 & 1.5119 & 1.5197 & 1.5367 & 1.5443 & 1.5433 & 1.5970 \\
\hline & $H^{\mathrm{E}}$ & 0.3098 & 0.3200 & 0.2948 & 0.3001 & 0.3067 & 0.3114 & 0.3129 & 0.3445 \\
\hline & $I$ & 0.4578 & 0.4764 & 0.4382 & 0.4463 & 0.4543 & 0.4614 & 0.4642 & 0.5138 \\
\hline & $\mathrm{P} / \%$ & 83.60 & 88.89 & 83.07 & 84.13 & 84.66 & 86.24 & 86.77 & 97.35 \\
\hline \multirow[t]{5}{*}{ ISSR } & $N_{\mathrm{A}}$ & 1.8480 & 1.8830 & 1.8421 & 1.8655 & 1.8713 & 1.9006 & 1.8947 & 1.9883 \\
\hline & $N_{\mathrm{E}}^{\mathrm{A}}$ & 1.5879 & 1.6048 & 1.5565 & 1.5842 & 1.5842 & 1.6221 & 1.6417 & 1.6539 \\
\hline & $H$ & 0.3308 & 0.3432 & 0.3166 & 0.3312 & 0.3312 & 0.3497 & 0.3584 & 0.3725 \\
\hline & $I$ & 0.4841 & 0.5035 & 0.4664 & 0.4865 & 0.4873 & 0.5116 & 0.5221 & 0.5492 \\
\hline & $\mathrm{P} / \%$ & 84.80 & 88.30 & 84.21 & 86.55 & 87.13 & 90.06 & 89.47 & 98.83 \\
\hline
\end{tabular}

ISSR $=$ inter-simple sequence repeat; RAPD $=$ random amplified polymorphic DNA. $N_{\mathrm{A}}=$ number of alleles; $N_{\mathrm{E}}$ = effective number of alleles; $H=$ heterozygosity; $I=$ Shannon's information index. For other abbreviations, see legend to Table 2 .

Analysis of RAPD data showed that the KDE, WYL, and YCYH regions displayed more variation, and the coefficients were $88.89,86.77$, and $86.24 \%$, respectively. According to the number of polymorphic loci, the ranking of the regions was $\mathrm{KDE}>\mathrm{WYL}>\mathrm{YCYH}>\mathrm{NJ}$ $>\mathrm{GH}>\mathrm{AES}>\mathrm{MEDG}$. In the ISSR analysis, the coefficients of the YCYH, WYL, and KDE regions were 90.06, 89.47, and 88.30\%, respectively, and the ranking was YCYH $>$ WYL $>$ $\mathrm{KDE}>\mathrm{NJ}>\mathrm{GH}>\mathrm{AES}>$ MEDG. Only the position of the KDE region was different in the 2 marker analyses, and the MEDG region showed the minimum variation. A significant correlation was found between RAPD and ISSR results (correlation coefficient, $r=0.762 *$ ).

Table 3 shows that a general consistency occurred between the ISSR and RAPD approaches in different indexes of genetic diversity, and the polymorphic locus percentages were both more than $90 \%$. This finding indicated high genetic variation among the L. gmelinii regions and that these 2 marker approaches were effective for detection.

\section{Regional genetic differentiation}

Total genetic diversity, genetic diversity within populations, and genetic diversity among populations were calculated using the data from the RAPD and ISSR approaches (Table 4). The RAPD results showed that $89.48 \%$ genetic variation existed within populations, whereas $10.52 \%$ variation was found between populations. The ISSR results revealed $90.57 \%$ variation within populations and only $9.43 \%$ between populations. The similarity of these results indicated that variation within populations was the main factor for genetic variation on a molecular level, and variation between populations was very small. Gene flow was determined to be 4.2626 and 4.8118 using RAPD and ISSR, respectively. Therefore, we speculated that a wide range of gene mixing occurred among populations and that population differentiation was inhibited.

Table 4. Genetic differentiation of regions.
\begin{tabular}{lcccc}
\hline & Total gene diversity $\left(H_{\mathrm{t}}\right)$ & Gene diversity within populations $\left(H_{\mathrm{s}}\right)$ & Gene diversity among populations $\left(D_{\mathrm{ST}}\right)$ & Gene flow $\left(N_{\mathrm{m}}\right)$ \\
\hline RAPD & 0.3441 & 0.3079 & 0.0362 & 4.2626 \\
ISSR & 0.3724 & 0.3373 & 0.0351 & 4.8118 \\
\hline
\end{tabular}

ISSR = inter-simple sequence repeat; RAPD = random amplified polymorphic DNA. 


\section{Genetic similarity and cluster analysis}

\section{Genetic similarity}

The genetic identity and distance of populations were calculated using the Nei (1978) method. The genetic identity was $0.9137-0.9601$ and the genetic distance was $0.0408-0.0903$ according to RAPD analysis (Table 5). These values were 0.9219-0.9563 and 0.0447-0.0814, respectively, according to ISSR data (Table 6). The relatively small change illustrated the close genetic relationship of the 7 regions.

Table 5. Nei's genetic identity (above diagonal) and genetic distance (below diagonal) (RAPD).

\begin{tabular}{lccccccc}
\hline Regions & AES & KDE & MEDG & GH & NJ & YCYH & WYL \\
\hline AES & - & 0.9497 & 0.9326 & 0.9343 & 0.9357 & 0.9137 & 0.9181 \\
KDE & 0.0516 & - & 0.9515 & 0.9601 & 0.9489 & 0.9323 & 0.9378 \\
MEDG & 0.0697 & 0.0497 & - & 0.9482 & 0.9293 & 0.9454 & 0.9250 \\
GH & 0.0680 & 0.0408 & 0.0532 & - & 0.9455 & 0.9396 & 0.9323 \\
NJ & 0.0664 & 0.0525 & 0.0733 & 0.0560 & - & 0.9459 & 0.9478 \\
YCYH & 0.0903 & 0.0701 & 0.0562 & 0.0623 & 0.0556 & 0.9484 \\
WYL & 0.0855 & 0.0642 & 0.0780 & 0.0700 & 0.0536 & 0.0530 & - \\
\hline
\end{tabular}

$\mathrm{RAPD}=$ random amplified polymorphic DNA. For abbreviations, see legend to Table 2.

Table 6. Nei's genetic identity (above diagonal) and genetic distance (below diagonal) (ISSR).

\begin{tabular}{lcccccrr}
\hline Regions & AES & KDE & MEDG & GH & NJ & YCYH & WYL \\
\hline AES & - & 0.9445 & 0.9469 & 0.9289 & 0.9563 & 0.9311 & 0.9314 \\
KDE & 0.0571 & - & 0.9484 & 0.9219 & 0.9479 & 0.9338 & 0.9441 \\
MEDG & 0.0546 & 0.0530 & - & 0.9539 & 0.9426 & 0.9319 & 0.9364 \\
GH & 0.0738 & 0.0814 & 0.0471 & - & 0.9327 & 0.9230 & 0.9305 \\
NJ & 0.0447 & 0.0535 & 0.0591 & 0.0697 & - & 0.9394 & 0.9444 \\
YCYH & 0.0714 & 0.0685 & 0.0706 & 0.0801 & 0.0625 & - & 0.9353 \\
WYL & 0.0711 & 0.0575 & 0.0657 & 0.0720 & 0.0572 & 0.0669 & - \\
\hline
\end{tabular}

ISSR $=$ inter-simple sequence repeat. For abbreviations, see legend to Table 2.

\section{Cluster analysis of genetic distance}

Genetic cluster analysis was conducted using the unweighted pair group method with arithmetic mean; we then constructed a genetic relationship dendrogram (RAPD shown in Figure 3; ISSR shown in Figure 4). As Figure 3 shows, the 7 regions were classified into 2 groups (Daxing' an and Xiaoxing' an Mountain ranges) at a genetic distance of 0.08. The AES, $\mathrm{KDE}, \mathrm{GH}$, and MEDG regions belonged to group I, whereas the other 3 regions (NJ, YCYH, and WYL) belonged to group II. The 7 regions were also divided into 3 groups at a genetic distance of 0.07: the AES region composed group I; the KDE, GH and MEDG regions composed group II, and the NJ, YCYH, and WYL regions composed group III. The Daxing'an Mountain range was divided into 2 groups, as the AES region has a long distance from the other 3 . The analysis for genetic distance and geographic locations of the L. gmelinii regions showed significant positive correlation (correlation coefficient, $r=0.752 *$ ). 


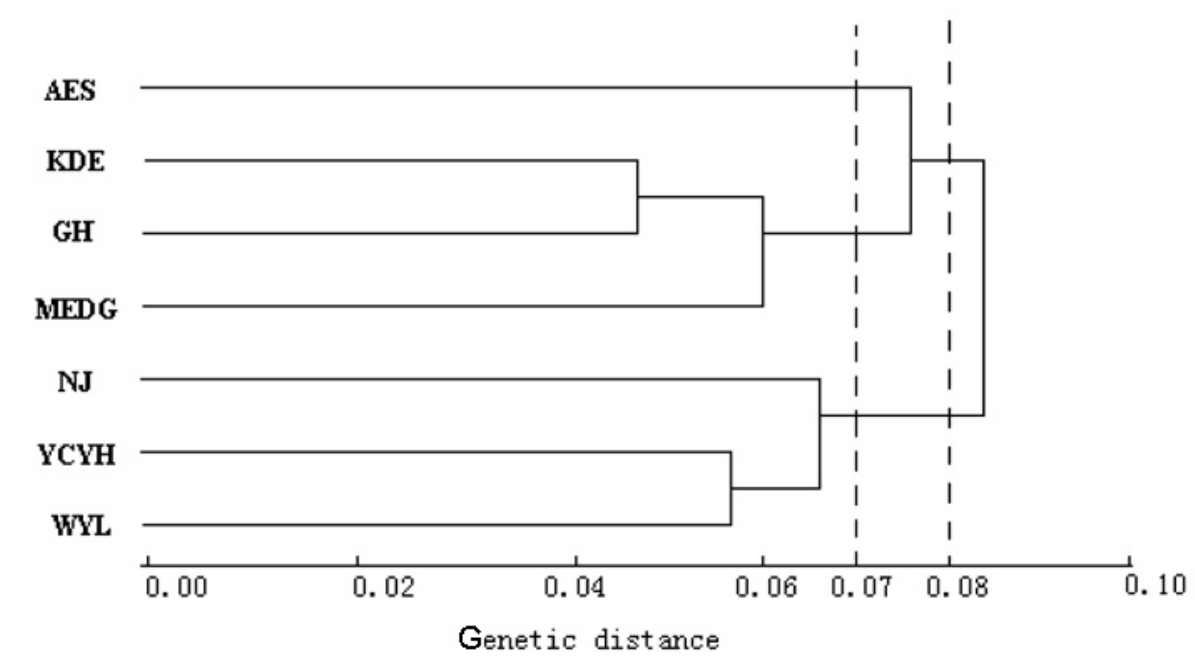

Figure 3. Genetic distance dendrogram for regions of Larix gmelinii using random amplified polymorphic DNA. For abbreviations, see legend to Table 2.

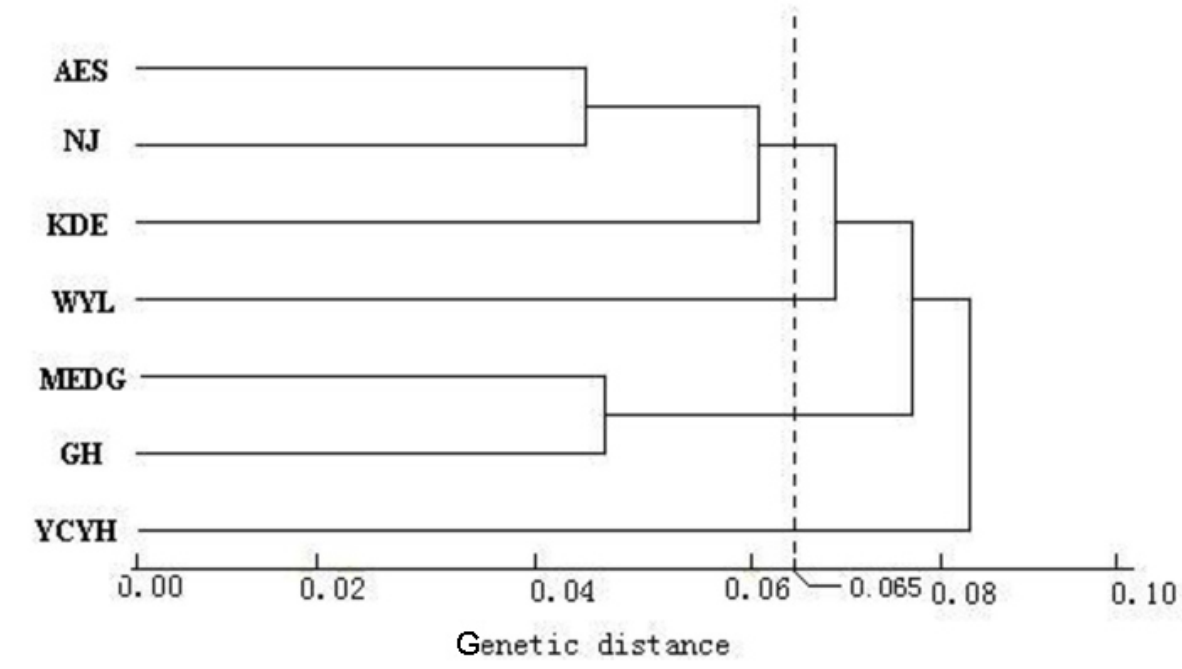

Figure 4. Genetic distance dendrogram for regions of Larix gmelinii using inter-simple sequence repeats. For abbreviations, see legend to Table 2 .

As Figure 4 shows, the 7 regions were classified into 4 groups: AES, NJ, and KDE belonged to group I; MEDG and GH belonged to group II; WYL belonged to group III, and YCYH belonged to group IV. The clustering of ISSR results showed that molecular findings were inconsistent with those of morphological studies; this result was also found in the RAPD results. Analysis between genetic features and geographic distance of the L. gmelinii regions was positively correlated but not significant (correlation coefficient, $r=0.219$ ). 


\section{Comprehensive analysis of growth, molecular marker, and geographic climate factors}

\section{Correlation analysis of growth and geographic factors}

The correlation analysis of growth and geographic factors showed a highly significant positive correlation between height and longitude and a significant negative correlation between height and elevation. Diameter was negatively correlated with latitude and elevation and positively correlated with longitude, but neither correlation was significant (Table 7).

Table 7. Correlation between geographic factors and growth characteristics.

\begin{tabular}{lccc}
\hline Characters & Longitude & Latitude & Elevation \\
\hline Height & -0.019 & 0.122 & -0.123 \\
Diameter & -0.046 & 0.022 & -0.019 \\
Volume & -0.025 & 0.061 & -0.065 \\
\hline
\end{tabular}

Significant correlation $(\mathrm{P}<0.05)$; very significant correlation $(\mathrm{P}<0.01)$.

Height, diameter, and volume were all very highly positively correlated with mean temperature in July and significantly negatively correlated with sunshine duration. Height and volume were both significantly positively correlated with absolute humidity, precipitation from May to July, and frost-free period, and a highly significant positive correlation was found between height and mean annual precipitation (Table 8).

Table 8. Correlation between climatic factors and growth characteristics.

\begin{tabular}{lcccccccccc}
\hline Character & $\begin{array}{c}\text { Mean } \\
\text { annual } \\
\text { temperature }\end{array}$ & $\begin{array}{c}\text { Mean } \\
\text { temperature } \\
\text { in January }\end{array}$ & $\begin{array}{c}\text { Mean } \\
\text { in July }\end{array}$ & $\begin{array}{c}\text { Accumulated } \\
\text { temperature } \\
\geq 10^{\circ} \mathrm{C}\end{array}$ & $\begin{array}{c}\text { Absolute } \\
\text { humidity }\end{array}$ & $\begin{array}{c}\text { Relative } \\
\text { humidity }\end{array}$ & $\begin{array}{c}\text { Mean } \\
\text { annual } \\
\text { precipitation }\end{array}$ & $\begin{array}{c}\text { Precipitation } \\
\text { from May } \\
\text { to July }\end{array}$ & $\begin{array}{c}\text { Sunshine } \\
\text { duration }\end{array}$ & $\begin{array}{c}\text { Frostless } \\
\text { period }\end{array}$ \\
Height & 0.075 & 0.037 & 0.264 & 0.231 & 0.166 & 0.057 & 0.136 & 0.153 & -0.163 & 0.181 \\
Diameter & -0.016 & -0.030 & 0.111 & 0.077 & 0.037 & -0.012 & 0.038 & 0.041 & -0.042 & 0.056 \\
Volume & 0.021 & -0.016 & 0.164 & 0.142 & 0.095 & 0.029 & 0.074 & 0.090 & -0.097 & 0.113 \\
\hline
\end{tabular}

Significant correlation $(\mathrm{P}<0.05)$; very significant correlation $(\mathrm{P}<0.01)$.

\section{Correlation analysis of the percentage of polymorphic loci and geographic climatic factors}

Polymorphic loci were an important indicator for determining the level of genetic variation of an area. A specimen with a high polymorphic locus rate showed a stronger capability for adaptation to the environment, whereas those with a weaker capability would be eliminated by natural selection.

The percentage of polymorphic loci in every region was negatively correlated with latitude and elevation and positively correlated with longitude, mean annual temperature, mean temperature in July, $\geq 10^{\circ} \mathrm{C}$ accumulated temperature, absolute humidity, relative humidity, mean annual precipitation, and frost-free period. Most findings of the correlation analysis using the ISSR method were found to be significant (Table 9). 


\begin{tabular}{|c|c|c|c|c|c|c|c|}
\hline & Longitude & Latitude & Elevation & $\begin{array}{l}\text { Mean annual } \\
\text { temperature }\end{array}$ & $\begin{array}{l}\text { Mean temperature } \\
\text { in January }\end{array}$ & $\begin{array}{l}\text { Mean temperature } \\
\text { in July }\end{array}$ & $\begin{array}{c}\text { Accumulated } \\
\text { temperature } \geq 10^{\circ} \mathrm{C}\end{array}$ \\
\hline PPB (ISSR) & -0.334 & 0.868 & -0.730 & 0.758 & 0.538 & 0.951 & 0.922 \\
\hline \multirow[t]{2}{*}{ PPB (RAPD) } & -0.189 & 0.413 & -0.242 & 0.231 & 0.268 & 0.861 & 0.591 \\
\hline & $\begin{array}{l}\text { Absolute } \\
\text { humidity }\end{array}$ & $\begin{array}{l}\text { Relative } \\
\text { humidity }\end{array}$ & $\begin{array}{l}\text { Mean annual } \\
\text { precipitation }\end{array}$ & $\begin{array}{l}\text { Precipitation from } \\
\text { May to July }\end{array}$ & $\begin{array}{l}\text { Sunshine } \\
\text { duration }\end{array}$ & Frost-free period & \\
\hline PPB (ISSR) & 0.839 & 0.544 & 0.870 & 0.748 & -0.829 & 0.841 & \\
\hline PPB (RAPD) & 0.412 & 0.074 & 0.713 & 0.334 & -0.393 & 0.419 & \\
\hline
\end{tabular}

$\mathrm{PPB}=$ percentage of polymorphic loci. Significant correlation $(\mathrm{P}<0.05)$; very significant correlation $(\mathrm{P}<0.01)$.

Analysis of growth characteristics and 2 molecular markers showed rich genetic variation among regions and individual samples of L. gmelinii. The YCYH region showed relatively richer genetic variation for growth - height, diameter, and volume coefficients of variation were $14.73,28.25$, and $55.27 \%$, respectively. The KDE region showed the least variation, with coefficients of variation of $12.69,18.03$, and $41.67 \%$, respectively.

The 23 RAPD and 21 ISSR primers detected 189 and 171 loci, respectively, and $184(97.35 \%)$ and $169(98.83 \%)$ were polymorphic. $I$ values were 0.5138 and 0.5492 , $N_{\mathrm{E}}$ values were 1.5970 and 1.6539 , and gene differentiation coefficients were 0.1050 and 0.0941 calculated by RAPD and ISSR data, respectively. RAPD results indicated that $10.52 \%$ variation was between populations and $89.48 \%$ within populations, whereas ISSR results showed that $9.43 \%$ variation existed within populations and $90.57 \%$ was between populations.

Height, diameter, and volume were all negatively correlated to latitude and elevation and positively correlated to longitude, and significant correlation was found between height and longitude. Polymorphic loci were negatively correlated with latitude and elevation but positively correlated to longitude and significantly correlated to mean July temperature and annual precipitation. These results illustrated that water and heat were the main climatic factors affecting the percentage of polymorphic loci.

\section{DISCUSSION}

\section{Analysis of genetic variation and genetic structure}

Our research found that the region with the best genetic variation in growth characteristics was YCYH, similar to findings in a trial in Maoershan (Yang et al., 2002). Results of ISSR and RAPD marker analyses both showed that genetic variation of L. gmelinii regions was mainly internal and less between populations. Findings for total gene diversity, gene diversity within populations, and gene diversity among populations were similar between the RAPD and ISSR approaches and showed only $10 \%$ variation among populations. This result was similar to those of previous genetic diversity analyses of most forestry tree populations (Lee, 2002; Wang and Gao, 2009). All of these results illustrate that the relatively high level of genetic diversity is distributed mainly within, rather than between, populations. 


\section{Evaluation of genetic similarity}

A very small difference in $I$ was found between the results of the RAPD and ISSR approaches. This finding indicated a closer relationship between regions and was consistent with the results of previous research on L. gmelinii regional genetic diversity (Yang et al., 2002). A small difference in clustering results was found between the 2 approaches. This slight variation may be caused by primer detection mechanisms: 1) the loci detected by RAPD and ISSR were different; for RAPD, the inverted repeats and internal site were amplified, whereas ISSR amplified inter-segment repeats, and 2) RAPD primers used random sequences of 10 bases, and ISSR primers were based on anchored primer repeats of 15-24 bases; therefore, polymorphism would be different, and the number of polymorphic fragments would increase with the increased number of primers and could also cause the change in genetic distance. Classification results were different by using different technology, as has been published in several studies (Messaoud et al., 2007; Majourhat et al., 2008).

\section{Comprehensive analysis of multiple indices}

Our results were consistent for the correlation between growth traits, molecular marker polymorphism, and geographic factors: a negative correlation was found with respect to the latitude and elevation, whereas a positive correlation to longitude was present. Similar findings have been published previously that cite a negative correlation between growth traits of L. gmelinii and latitude and a positive correlation to longitude, forming a geographic variation model of latitude and longitude as a double-continuous gradient mainly based on longitude and latitude (Yang et al., 2002).

The findings of correlation between genetic distance and geographic distance using RAPD and ISSR analyses showed that the 2 markers were both positively correlated and illustrated that genetic distance is more closely related to geographic distance; this finding was similar to other conclusions on genetic variation in most species (Raymond and Ledig, 1982; Zemanová et al., 2004). Correlation was significant for RAPD markers (correlation coefficient, 0.752); however, a positive but not significant correlation for ISSR markers was found (correlation coefficient, 0.219). These results were similar to previous ISSR findings for L. gmelinii regional genetic diversity (correlation coefficient of 0.53 , significant positive correlation) (Na et al., 2006). According to the comparison of genetic cluster analyses, results for RAPD markers were more significant. Therefore, researchers should select several marker methods to obtain information on DNA variability when studying the genetic diversity of germplasms using molecular markers, as the resulting clustering analysis will be more accurate with this approach.

\section{ACKNOWLEDGMENTS}

Research supported by the National Technology Fundamental Work (\#2007FY110400-3).

\section{REFERENCES}

Bucci G, Vendramin GG, Lelli L and Vicario F (1997). Assessing the genetic divergence of Pinus leucodermis Ant. endangered populations: use of molecular markers for conservation purposes. Theor. Appl. Genet. 95: 1138-1146. 
Changtragoon S (1995). Inheritance of isozyme phenotypes of Pinus merkusii. J. Trop. For. Sci. 8: 167-177.

Goto S, Thakur RC and Ishii K (1998). Determination of genetic stability in long-term micropropagated shoots of Pinus thunbergii Parl. using RAPD markers. Plant Cell Rep. 18: 193-197.

Labra M, Grassi F, Sgorbati S and Ferrari C (2006). Distribution of genetic variability in southern populations of Scots pine (Pinus sylvestris L.) from the Alps to the Pennines. Flora Morph. Distrib. Func. Ecol. Plants 201: 468-476.

Larionova AI, Iakhneva NV and Abaimov AP (2004). Genetic diversity and differentiation of Gmelin larch Larix gmelinii populations from Evenkia (Central Siberia). Genetika 40: 1370-1377.

Lee SW, Ledig FT and Johnson DR (2002). Genetic variation at allozyme and RAPD markers in Pinus longaeva (Pinaceae) of the White Mountains, California. Am. J. Bot. 89: 566-577.

Li W (2004). Study on genetic diversity of Pinus sibirica du tour with ISSR-PCR. Northeast For. Univ.

Liu GF, Dong JX, Jiang Y, Lu YF, et al. (2005). Analysis of genetic relationship in 12 species of Section Strobus with ISSR markers. J. For. Res. 16: 213-215.

Majourhat K, Jabbar A, Hafidi A and Martínez-Gomez P (2008). Molecular characterization and genetic relationships among most common identified morphotypes of critically endangered rare Moroccan species Argania spinosa (Sapotaceae) using RAPD and SSR markers. Ann. For. Sci. 65: 805.

Messaoud C, Afif M, Boulila A, Rejeb MN, et al. (2007). Genetic variation of Tunisian Myrtus communis L. (Myrtaceae) populations assessed by isozymes and RAPDs. Ann. For. Sci. 64: 845-853.

$\mathrm{Na}$ D, Yang C and Jiang J (2006). Analysis on the genetic diversity of Larix gmelinii provenance by using ISSR markers. For. Sci. Tech. 31: 1-4.

Nei M and Li WH (1979). Mathematical model for studying genetic variation in terms of restriction endonucleases. Proc. Natl. Acad. Sci. U. S. A. 76: 5269-5273.

Oreshkova NV, Larionova AY, Milyutin LI and Abaimov AP (2006). Genetic diversity structure and differentiation of Gmelin Larch (Larix gmelinii (Rupr.) Rupr.) populations from Central Evenkia and Eastern Zabaikalje. Eurasian J. For. Res. 9-1: 1-8.

Porebski S, Bailey LG and Baum BR (1997). Modification of a CTAB DNA extraction protocol for plants containing high polysaccharide and polyphenol components. Plant Mol. Biol. Rep. 15: 8-15.

Raymond PG and Ledig FT (1982). Genetic diversity and population structure in pitch pine (Pinus rigida mill.). Evolution 36: 387-402.

Shahraji TR, Kazempour MN and Adbesh Z (2009). Genetic (RAPD) diversity in loblolly pine unknown provenance plantation in Iran. Indian J. Hortic. 66: 35-38.

Wang MB and Gao FQ (2009). Genetic variation in Chinese pine (Pinus tabulaeformis), a woody species endemic to China. Biochem. Genet. 47: 154-164.

Xue X, Wang Y, Korpelainen H and Li C (2007). Genetic diversity of Picea asperata populations based on RAPDs. Plant Biol. 9: 101-108.

Yang CP, Jiang J, Tang SS, Li JY, et al. (2002). The provenance test of 21-year Old Larix gmelinii at Maoershan area. J. Northeast For. Univ. 30: 6.

Yeh FC, Yang R and Boyle T (1999). POPGENE, Version 1.31, Microsoft Window-Based Freeware for Population Genetic Analysis. Centre for International Forestry Research, University of Alberta and Tim Boyle. Available at [http://www.ualberta.ca/ fyeh/popgene.pdf]. Accessed August 30, 1999.

Zemanová E, Jirku M, Mauricio IL, Miles MA, et al. (2004). Genetic polymorphism within the Leishmania donovani complex: correlation with geographic origin. Am. J. Trop. Med. Hyg. 70: 613-617.

Zhang HG, Wang H, Xiao Y and Zhang CF (2002). Population genetic diversity of Picea koraiensis with allozyme techniques. J. Northeast For. Univ. 30: 21-25. 